\title{
Assessment of the quality of life of Egyptian and Tunisian autoimmune bullous diseases' patients using an Arabic version of the autoimmune bullous disease quality of life and the treatment of autoimmune bullous disease quality of life questionnaires*
}

\author{
Marwah Adly Saleh ${ }^{1}$, Ines Zaraa ${ }^{2}$, Nejib Doss ${ }^{3}$, Noha Adly Saleh ${ }^{1}$, Dedee F. Murrell ${ }^{4}$
}

DOI: http:/ /dx.doi.org/10.1590/abd1806-4841.20197198

\begin{abstract}
BACKGROUND: The Autoimmune Bullous Disease Quality of Life (ABQOL) and the Treatment of Autoimmune Bullous Disease Quality of Life (TABQOL) questionnaires proved to be reliable tools that measure the disease and treatment burden. OвJEctives: We aimed to assess the ABQOL and TABQOL in the Arabic population.

METHODs: The English questionnaires were translated into the Arabic language by a certified translation agency. Eighty autoimmune bullous disease (AIBD) patients were included in this study. Patients were asked to answer 2 questionnaires. After 1 week the same patients were asked to answer the same questionnaires again.

RESULTS: The age of the patients ranged from 19 to 81 years (mean=46), 19 males, 61 females. The ABQOL ranged from 0-37 (mean=16.4 \pm 9.2$)$. The TABQOL ranged from 2-43 (mean=21.5 \pm 9.4$)$. Test-retest reliability was acceptable, Cronbach's alpha was 0.76 for $\mathrm{ABQOL}$ and 0.74 for TABQOL. There was no significant correlation between the age of the patients and ABQOL, $\mathrm{r}$ $=-0.2$, $\mathrm{p}$ value was 0.183 . There was a significant negative correlation between the age of the patients and the TABQOL, $\mathrm{r}=-0.2$, $\mathrm{p}$ value was 0.039 . There was a significant negative correlation between the education of the patients and the TABQOL, $r=-0.3$, p value was 0.007 .

STUDY LIMITATIONS: Small sample size of some AIBDs and patients with severe disease.

CONCLUSION: Objective and valuable measurements such as ABQOL and TABQOL are now available to help physicians understand their patient's distress and should be used in every patient with AIBD. Younger and less educated patients appear to have more effects on their QOL from the treatments.
\end{abstract}

Keywords: Arab world; Arabs; Autoimmune diseases; Pemphigus; Pemphigoid, bullous; Quality of life; Skin diseases, vesiculobullous

\section{INTRODUCTION}

Autoimmune bullous diseases are a group of chronic potentially lethal autoimmune skin diseases. ${ }^{1,2}$ Those diseases are common in the Arabic population. ${ }^{3}$ An endemic form of those diseases is present in Brazil and Tunisia. ${ }^{4,5}$ These diseases are characterized by cutaneous blisters and mucosal erosions. Not only the pain, erosions and disfigurement of those diseases affect the patients' quality of life, but also the inability to work and the financial status add to their burden.
The Autoimmune Bullous Disease Quality of Life (ABQOL) and the Treatment of Autoimmune Bullous Disease Quality of Life (TABQOL) questionnaires were developed and validated in 2013 and 2014 respectively. ${ }^{6,7}$ Each of these questionnaires consists of 17 items, scored 0-3 for each of the 4 options (all the time, sometimes, occasionally and never), with final maximum score of 51, where higher scores represent worse quality of life. The questions of ABQOL focus on the pain, itching, healing, depression and anxiety. The questions of TABQOL focus on the number of medications, financial

\footnotetext{
Received 10 April 2017.

Accepted 07 May 2018.

Study conducted at the Department of Dermatology, Cairo University, Cairo, Egypt; Department of Dermatology, La Rabta Hospital,Tunis, Tunisia; Université de Tunis El Manar- Military Hospital of Tunis, Department of Dermatology, Tunis, Tunisia.

Financial support: None.

Conflict of interest: None.

Department of Dermatology, Faculty of Medicine, Cairo University, Cairo, Egypt.

Dermatology Department, La Rabta Hospital, Universite Tunis, EL Manar, Tunisia.

Department of Dermatology, Université de Tunis El Manar - Military Hospital of Tunis, Tunis, Tunisia.

Department of Dermatology, St George Hospital, Faculty of Medicine, UNSW Medicine, Australia.
}

E-mail: salehmarwah@kasralainy.edu.eg 
difficulties, lethargy, clear thinking and fear of relapse.

In this work we aimed to revalidate the ABQOL and TABQOL in Arabic as used in Egypt and Tunisia and assess quality of life and the effect of treatment on the quality of life in our autoimmune blistering disease patients.

\section{METHODS}

The original English questionnaires were developed by the Australian group. After signing an agreement with the developer of the original questionnaires, the validated English questionnaires (ABQOL and TABQOL) were forward-translated into the Arabic language by a certified translation agency (Cairo translation, Cairo, Egypt). To make sure the translation was correct, the Arabic questionnaire was back-translated to English language by an independent certified translation agency which did not have access to the original English version (ICU translation, Cairo, Egypt). This back translation was then read by the developer (DFM) to check that the meaning was the same in English as the original questionnaires.

In this cross-sectional cohort study, which was conducted from January 2015 until February 2016, all autoimmune bullous disease patients seen at the Dermatology outpatient clinics of 3 hospitals were included. The pemphigus patients' disease severity was evaluated by the validated Pemphigus Disease Area Index (PDAI). ${ }^{8}$ All the autoimmune bullous disease patients were interviewed in person and were asked to answer the questions in the 2 questionnaires. Patients who were able to read were given the questionnaires; however, where patients were illiterate, the questions were read to them by the doctors. After one week the same patients were asked to answer the same questionnaire again. Those who were illiterate had the help of a relative who could read, and the surveys were sent back in stamped, addressed envelopes.

Written informed consents were obtained from all the patients and the study was conducted according to the Principles of the Declaration of Helsinki. This work was approved by the ethical committee of the dermatology department.

Data was statistically described in terms of mean, standard deviation (SD), median and range, or frequencies (number of cases) and percentages when appropriate. T-test was used to compare the ABQOL and TABQOL between males and females. Bland and Altman plot was used for test-retest reliability and intraclass correlation. ${ }^{9}$ Internal consistency of the questionnaires was calculated using Cronbach's alpha. A multivariate analysis and multiple linear regressions were used for covariates. Pearson moment correlation equation and Spearman rank correlation were used for correlations. $P$ values less than 0.05 were considered statistically significant. All statistical analysis was done using GraphPad prism 5 for Windows (San Diego, California, USA) and Microsoft Excel 2010 for Windows.

\section{RESULTS}

Eighty autoimmune bullous disease patients were included in this study. Fifty-four patients were Egyptians and 26 were Tunisians. The majority of patients had pemphigus vulgaris (PV); $63(78.8 \%)$, followed by pemphigus foliaceus (PF); 6 (7.5\%), then mucous membrane pemphigoid (MMP); 5 (6.3\%), then pemphigus herpetiformis (PH); $3(3.8 \%)$, then epidermolysis bullosa acquisita
(EBA); 2 (2.5\%) and finally bullous pemphigoid (BP); 1 (1.3\%). The patients' data are summarized in table 1 . The age range was from 19 to 81 years and mean of 46 years; 19 were males, 61 females.

The average time to finish the Autoimmune Bullous Disease Quality of Life (ABQOL) questionnaire among the literate patients was 6.6 minutes. The average time to finish the Treatment of Autoimmune Bullous Disease Quality of Life (TABQOL) questionnaire among the literate patients was 5.7 minutes. The ABQOL ranged from 0-37 (mean was 16.4 \pm 9.2 ). The TABQOL ranged from 2-43 (mean was 21.5 \pm 9.4 )

The questions were easily understood by the patients. However, it was difficult for the illiterate patients to differentiate the meaning of the words "sometimes" from "occasionally". Question 7 in the ABQOL about bleeding gums was not applicable for 2 patients who had bleeding nose instead. Also, question 13 about the effect of blistering disease on sexual life was not applicable for unmarried females, males and also for widows because there is no sexual life without marriage in the Arabic population. Three females were virgins and 2 were widows. Question 16 about the disease effect on the holidays was not applicable for $50(63 \%)$ patients as they said they do not take any holidays. Question 17 about the employers' discrimination between the patients and other employees was not applicable for patients who were not employed or were running their own business. Fifty patients were not employed and three were running their own business. Eleven patients reported that summer was

\begin{tabular}{|c|c|c|c|}
\hline & Egyptians & Tunisians & Total \\
\hline Number & 54 & 26 & 80 \\
\hline \multicolumn{4}{|l|}{ Disease } \\
\hline PV & 47 & 16 & 63 \\
\hline PF & 0 & 6 & 6 \\
\hline $\mathrm{PH}$ & 0 & 3 & 3 \\
\hline $\mathrm{BP}$ & 0 & 1 & 1 \\
\hline MMP & 5 & 0 & 5 \\
\hline EBA & 2 & 0 & 2 \\
\hline \multicolumn{4}{|l|}{ Sex } \\
\hline males & 10 & 9 & 19 \\
\hline females & 44 & 17 & 61 \\
\hline \multicolumn{4}{|l|}{ Age } \\
\hline range (years) & $19-72$ & $23-81$ & $19-81$ \\
\hline mean & $42.6 \pm 12.4$ & $52.8 \pm 15.9$ & $46 \pm 14$ \\
\hline \multicolumn{4}{|l|}{ Disease score } \\
\hline range & $0-55$ & $0-55$ & \\
\hline median & 3 & 5 & \\
\hline \multicolumn{4}{|l|}{ Education } \\
\hline literate & 9 & 7 & 16 \\
\hline Illiterate & 45 & 19 & 64 \\
\hline
\end{tabular}


worse for them, while 5 patients reported that winter was worse.

Twenty-eight (35\%) patients complained of pain. Forty-seven (58.8\%) patients believed they received a lot of medications. Thirty-seven $(46 \%)$ patients could not afford their treatment and depended on donations to buy the medications (Figure 1).

The internal consistency for the ABQOL and TABQOL was calculated by Cronbach's alpha. Cronbach's alpha for ABQOL and TABQOL was 0.76 and 0.74 respectively. Bland-Altman was used to calculate intraclass correlations. ABQOL has 95\% agreement between -1.6-2.3. TABQOL has 95\% agreement between -3.06-1.8 (Figure 2). Bland-Altman was used to calculate the bias of test-retest. It was 0.1 for ABQOL with 95\% agreement between -1.6 to 1.8. The bias was -0.05 for TABQOL with $95 \%$ agreement between -2.1 to 2.0 (Figure 3).

The ABQOL in females ranged from 0-36 (mean=16.3 \pm 8.6 ). The ABQOL in males ranged from 0-37 (mean=16.5 \pm 10.9 ). There was no significant difference between females and males; $\mathrm{p}$ value was 0.950. The TABQOL in females ranged from 5-43 (mean=22.5 \pm 9 ). The TABQOL in males ranged from 2-35 (mean=19.5 \pm 8.9 ). There was no significant difference between females and males; $p$ value

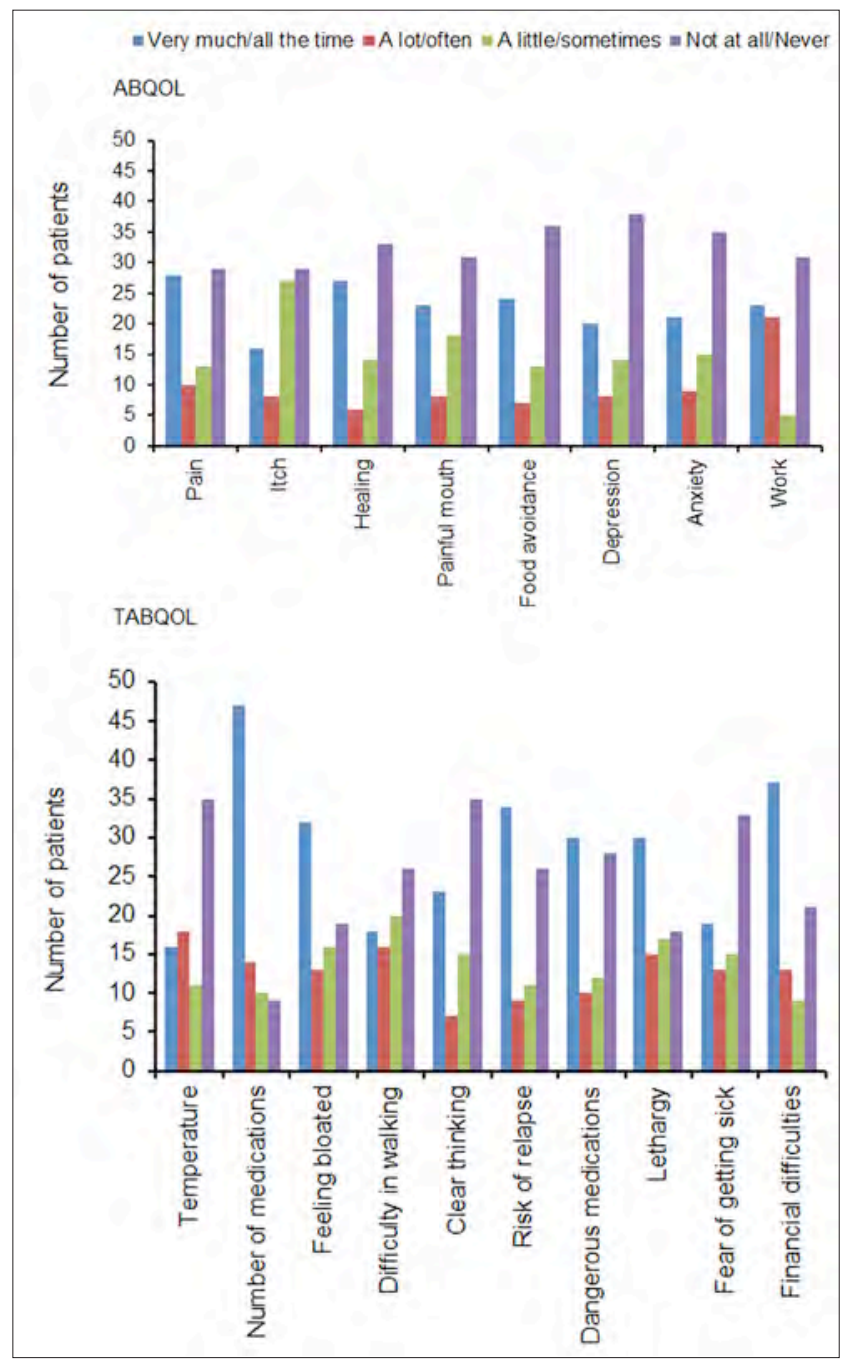

FIGURE 1: The response of the patients to some of the questions of the ABQOL and TABQOL questionnaires

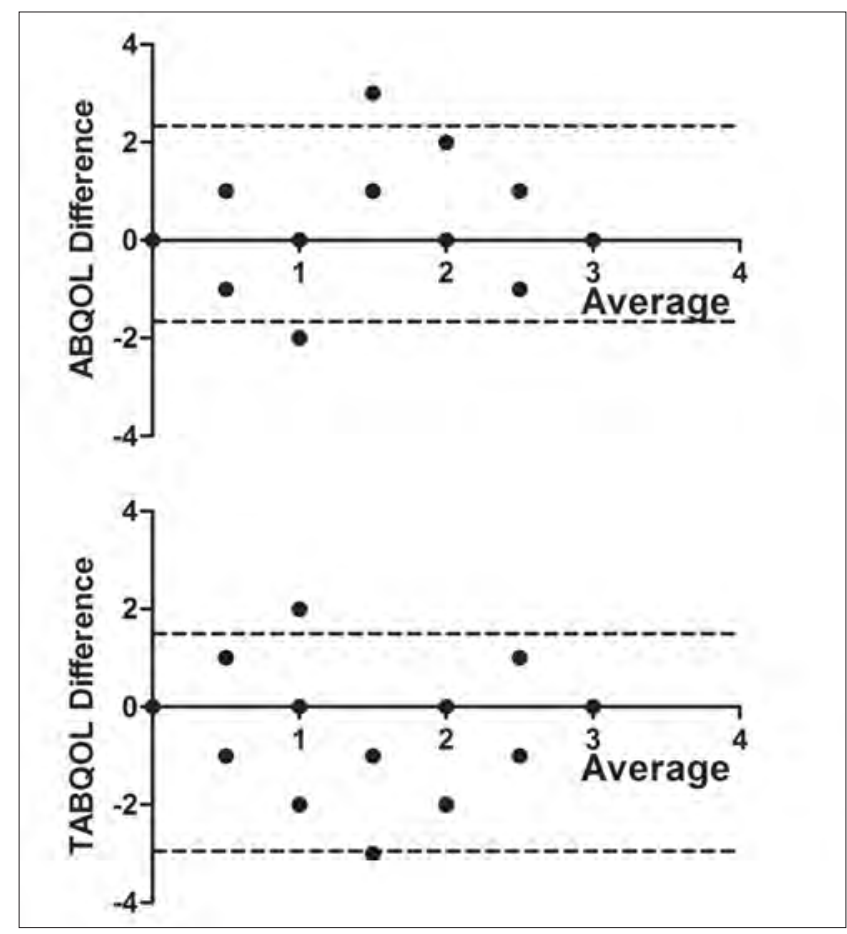

FIGURE 2: Bland-Altman plot of intraclass correlation of ABOOL and TABQOL. The dotted line represents the $95 \%$ interval for distributions of measurement differences

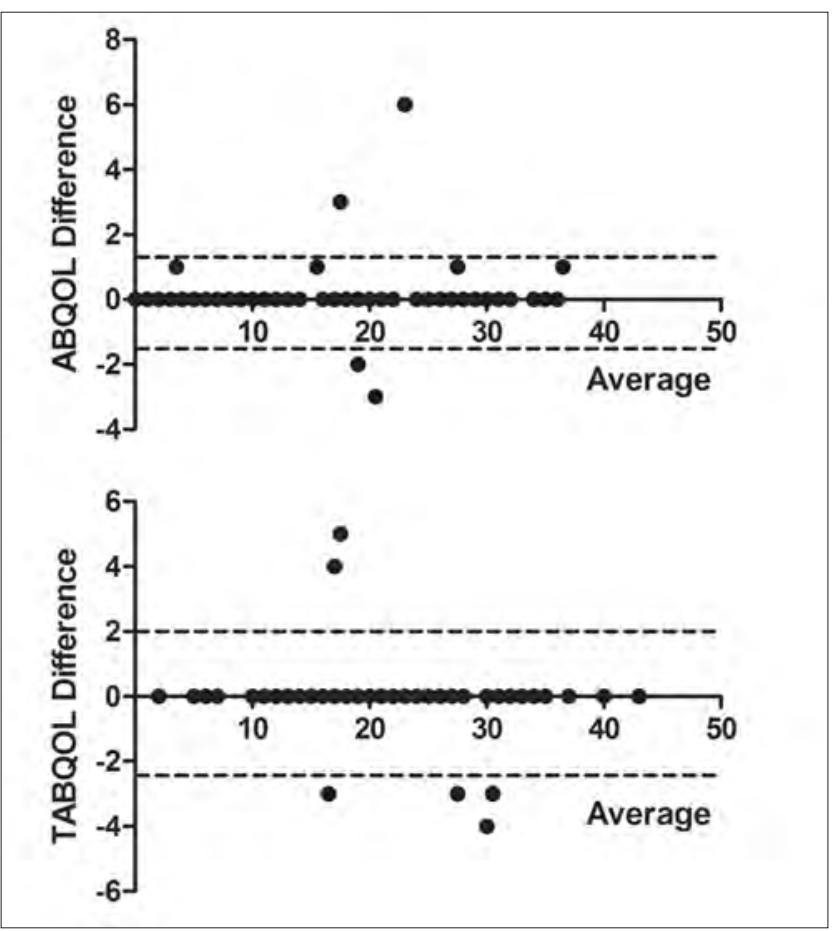

FIGURE 3: Bland-Altman plot of difference between Test and retest of ABQOL and TABQOL against mean measurements. The dotted line represents the $95 \%$ interval for distributions of measurement differences 
was 0.191.

The only BP patient in this study had the highest ABQOL (34) and TABQOL (35) scores. Among the pemphigus group, PF patients had the highest ABQOL (mean=19 \pm 3.7 ) while PV patients had the highest TABQOL score (mean=21.6 \pm 9.6 ) (Figure 4).

There was no significant correlation between the education of the patients and the ABQOL; $r=0.1, p$ value was 0.374 . There was a significant moderate negative correlation between the education of the patients and the TABQOL; $r=-0.3, p$ value was 0.007 . The mean Pemphigus Disease Area Index (PDAI) score of the literate patients was 7 and the mean PDAI score of the illiterate patients was 6.1. There was no significant difference between the PDAI of the literate and illiterate patients, $p$ value was 0.962 . There was no significant correlation between the disease score and the ABQOL; $r=0.2$, $\mathrm{p}$ value was 0.091 . There was no significant correlation between the disease score and the TABQOL; $r=0.07, \mathrm{p}$ value was 0.527 . Patients in flare had the highest ABQOL and TABQOL scores (Figure 5).

There was no significant correlation between the age of the patients and ABQOL; $r=-0.2$, $p$ value was 0.183 . There was a significant low negative correlation between the age of the patients and the TABQOL; $r=-0.2$, $p$ value was 0.039 . When evaluated in a multivariate manner, higher TABQOL was associated with younger and less educated patients (Table 2). The sex, age, education and disease severity could not predict the ABQOL, $\mathrm{r}^{2}$ was $0.001,0.02,0.01$ and 0.01 respectively, $p$ values were $0.695,0.206,0.374$ and 0.282 respectively. The age and education were able to predict the TABQOL, $\mathrm{r}^{2}$ was 0.07 and $0.08, p$ values were 0.022 and 0.009 respectively. The sex and disease severity could not predict the TABQOL, $\mathrm{r}^{2}$ was 0.006 and 0.02 , $p$ values were 0.502 and 0.284 respectively.

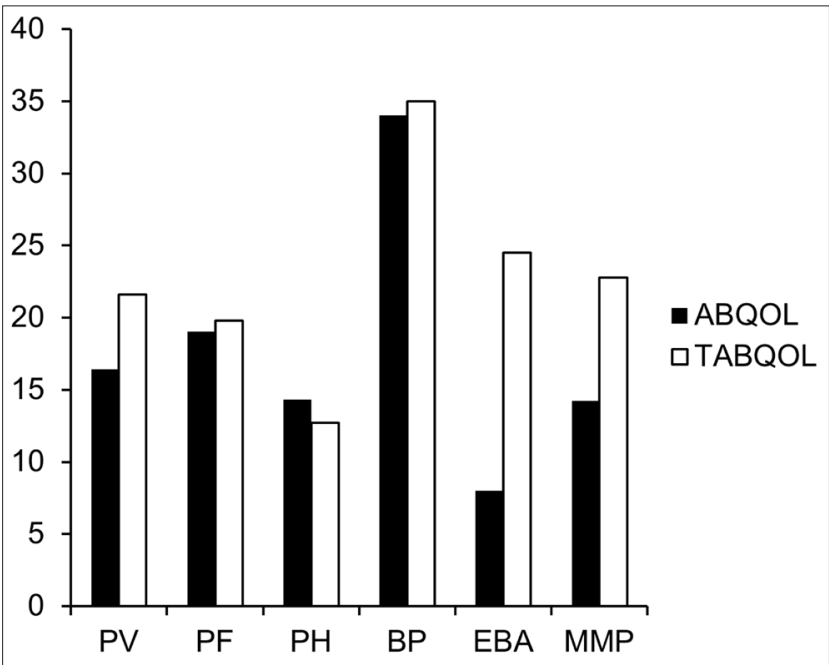

Figure 4: Mean score for each subtype of autoimmune bullous disease. Higher scores indicate greater quality of life impact. PV, pemphigus vulgaris; $\mathrm{PF}$, pemphigus foliaceus; $\mathrm{PH}$, pemphigus herpetiformis; BP, bullous pemphigoid; EBA, epidermolysis bullosa acquisita and MMP, mucous membrane pemphigoid

\section{DISCUSSION}

Many quality of life questionnaires were translated and validated in different languages, such as, for example, the acne specific quality of life questionnaire, Skindex-29 and Short form health survey-36. ${ }^{10-12}$ In this work we tried to determine the quality of life of autoimmune bullous diseases in the Arabic population using the ABQOL and the TABQOL. The questionnaires were consistent as determined by Cronbach alpha. PV was over expressed in our study, which reflects the higher incidence of the disease compared to the other autoimmune bullous diseases in the Arabic populations. ${ }^{3}$ Our results showed that the only $\mathrm{BP}$ patient who was included in this study had the highest ABQOL score followed by PV patients. The
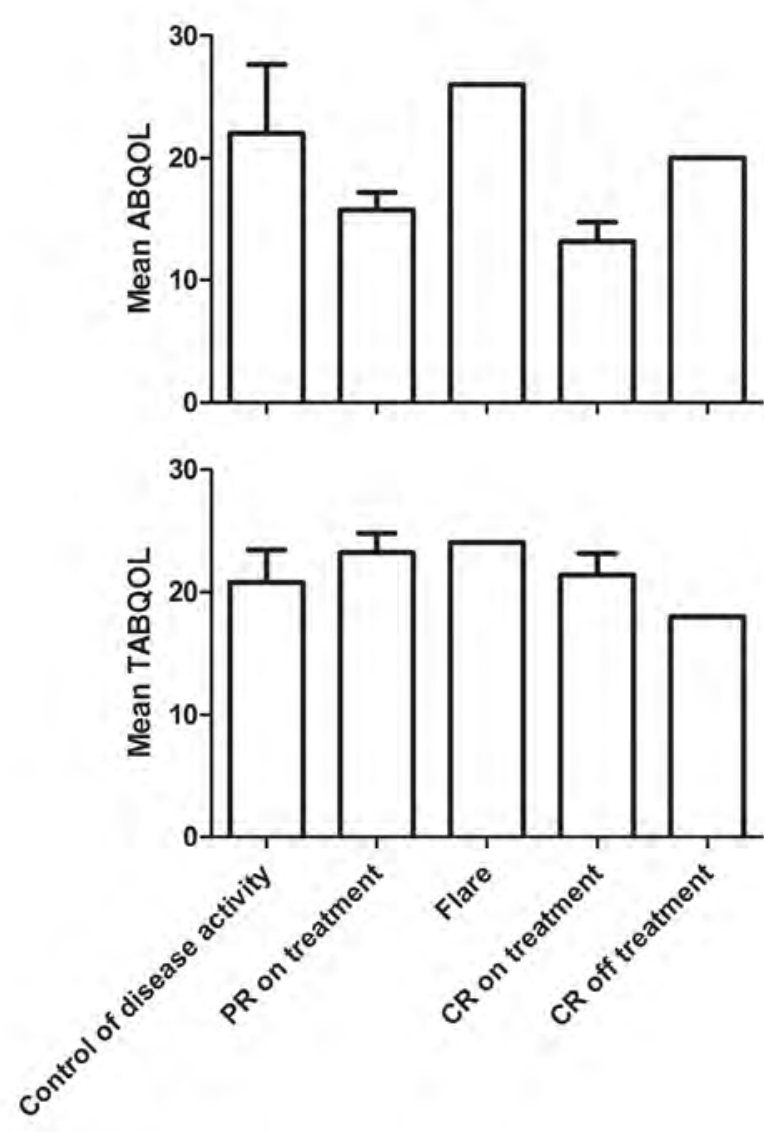

FIgURE 5: Mean score for ABQOL and TABQOL according to the disease stage. $\mathrm{CR}$, complete remission; $\mathrm{PR}$, partial remission

\section{TABLE 2: Multivariate analysis of ABQOL and TABQOL} according to demographic and clinical variables

\begin{tabular}{lcccc} 
& ABQOL & \multicolumn{3}{c}{ TABQOL } \\
\hline Variable & $\begin{array}{c}\text { Coefficient } \\
\beta\end{array}$ & p-value & $\begin{array}{c}\text { Coefficient } \\
\beta\end{array}$ & $p$-value \\
Age & -0.08 & 0.267 & -0.18 & 0.008 \\
\hline Gender & 0.96 & 0.695 & 1.13 & 0.604 \\
\hline PDAI & -0.09 & 0.288 & -0.08 & 0.336 \\
\hline $\begin{array}{l}\text { Reading } \\
\text { ability }\end{array}$ & 1.8 & 0.418 & -6.0 & 0.004 \\
\hline
\end{tabular}


BP patient also had the highest TABQOL score followed by EBA.

We compared the quality of life of the Arabic populations with autoimmune bullous diseases to those of other populations: ABQOL in PV patients was 16.4 in the Arabic population while it was 11.5 in the Australian and New Zealand populations. ${ }^{6}$ The ABQOL of the American population with PV was $16.4 .{ }^{13}$ TABQOL in PV patients was 21.6 in the Arabic population while it was 17.35 in the Australian and New Zealand populations. ${ }^{7}$ Moreover, the TABQOL in PF patients was 19.8 in the Arabic population while it was 16 in the Australian and New Zealand populations. Interestingly, the TABQOL of the Arabic as well as Australian and New Zealand populations with EBA was 24.5.

A limitation of this work is the small number of patients with severe disease. Severe disease is defined as PDAI $>25 .{ }^{14}$ There was no significant correlation between the disease score and the ABQOL and the TABQOL. This might be due to that $64 \%$ of our patients had $\mathrm{PDAI}<5$. On the other hand, it might point out that the visible clinical disease does not reflect the quality of life of the patients. Patients with PDAI $<5$ felt itching and burning skin, noticed slowly healing skin after any wound, had painful oral erosions or even had painful oral mucosa without erosion, felt depressed from their disease. Moreover, they felt that they were taking many medications, felt it was difficult to walk, were worried that their disease will get worse once they drop the dosages of their medications, always felt tired and lethargic, stopped some activities to avoid getting sick and were having financial difficulties.
There was no significant difference between males and females in the ABQOL and TABQOL. This contradicts the results of an Italian and a Brazilian study which showed that females had poorer quality of life scores. ${ }^{15,16}$ There was low significant negative correlation between the age of the patients and TABQOL. This might suggest that the impact of the treatment of autoimmune bullous disease on the quality of life is higher in young than old patients. Moreover, there was low significant negative correlation between the education of the patient and the TABQOL. This is in agreement with a study done in the Brazilian population which showed that less educated patients have poorer quality of life scores. ${ }^{16}$ This might be due to the fact that illiterate patients are less likely to understand medical prescriptions, more liable to confuse their medical regimen and, therefore, their treatment has more impact on their quality of life.

\section{CONCLUSION}

Objective and valuable measurements such as ABQOL and TABQOL questionnaires are now available to help physicians understand their patient's distress and should be used in every patient with AIBD.

\section{ACKNOWLEDGMENTS}

We acknowledge our patients who volunteered to answer the questionnaires. We thank professor Mohamed Hussein Medhat El-Komy (Cairo University) who agreed to include some of his patients in this study. 


\section{REFERENCES}

1. Bystryn JC, Rudolph JL. Pemphigus. Lancet. 2005;366:61-73.

2. Stanley JR. Pemphigus and pemphigoid as paradigms of organ-specific, autoantibody-mediated diseases. J Clin Invest. 1989;83:1443-8.

3. Saleh MA. Pemphigus in the Arab world. J Dermatol. 2015;42:27-30.

4. Aoki V, Rivitti EA, Diaz LA. Update on fogo selvagem, an endemic form of pemphigus foliaceus. J Dermatol. 2015:42:18-26.

5. Toumi A, Saleh MA, Yamagami J, Abida O, Kallel M, Masmoudi A et al. Autoimmune reactivity against precursor form of desmoglein 1 in healthy Tunisians in the area of endemic pemphigus foliaceus. $J$ Dermatol Sci. 2013;70:19-25.

6. Sebaratnam DF, Hanna AM, Chee SN, Frew JW, Venugopal SS, Daniel BS, et al. Development of a quality-of-life instrument for autoimmune bullous disease: the Autoimmune Bullous Disease Quality of Life questionnaire. JAMA Dermatol. 2013;149:1186-91.

7. Tjokrowidjaja A, Daniel BS, Frew JW, Sebaratnam DF, Hanna AM, Chee $\mathrm{S}$, al. The development and validation of the treatment of autoimmune bullous disease quality of life questionnaire, a tool to measure the quality of life impacts of treatments used in patients with autoimmune blistering disease. Br J Dermatol. 2013;169:1000-6.

8. Rosenbach M, Murrell DF, Bystryn JC, Dulay S, Dick S, Fakharzadeh S et al. Reliability and convergent validity of two outcome instruments for pemphigus. J Invest Dermatol. 2009:129:2404-10.

9. Miot HA. Agreement analysis in clinical and experimental trials. J Vasc Bras .2016:15:89-92.
10. Kamamoto Cde S, Hassun KM, Bagatin E, Tomimori J. Acne-specific quality of life questionnaire (Acne-QoL): translation, cultural adaptation and validation into Brazilian-Portuguese language. An Bras Dermatol. 2014;89:83-90.

11. Paula HR, Haddad A, Weiss MA, Dini GM, Ferreira LM. Translation, cultural adaptation, and validation of the American Skindex-29 quality of life index. An Bras Dermatol. 2014 Jul-Aug;89(4):600-7.

12. Augustin $M$, Wenninger $K$, Amon U, Schroth MJ, Küster W, Chren M, et al. German adaptation of the Skindex-29 questionnaire on quality of life in dermatology: validation and clinical results. Dermatology. 2004;209:14-20.

13. Sebaratnam DF, Okawa J, Payne A, Murrell DF, Werth VP. Reliability of the autoimmune bullous disease quality of life (ABQOL) questionnaire in the USA. Qual Life Res. 2015;24:2257-60.

14. Murrell DF, Peña S, Joly P, Marinovic B, Hashimoto T, Diaz LA, et al. Diagnosis and Management of Pemphigus: recommendations by an International Panel of Experts. J Am Acad Dermatol. 2018. pii: S01909622(18)30207-X

15. Paradisi A, Sampogna F, Di Pietro C, Cianchini G, Didona B, Ferri R, et al. Quality-of-life assessment in patients with pemphigus using a minimum set of evaluation tools. J Am Acad Dermatol. 2009;60:261-9.

16. Penha MA, Farat JG, Miot HA, Barraviera SR. Quality of life index in autoimmune bullous dermatosis patients. An Bras Dermatol. 2015;90:190-4

\section{AUTHORS' CONTRIBUTIONS}

Marwah Adly Saleh

(1D) ORCID

0000-0002-9487-8708

Statistical analysis, Elaboration and writing of the manuscript, Obtaining, analyzing and interpreting the data, Effective participation in research orientation, Intellectual participation in propaedeutic and/or therapeutic conduct of the cases studied, Critical review of the literature, Critical review of the manuscript.

\section{Ines Zaraa \\ (iD) ORCID \\ 0000-0003-1886-3528}

Approval of the final version of the manuscript, Obtaining, analyzing and interpreting the data, Effective participation in research orientation, Intellectual participation in propaedeutic and/or therapeutic conduct of the cases studied, Critical review of the manuscript.
Nejib Doss
(iD) ORCID
0000-0002-9222-2051

Approval of the final version of the manuscript, Obtaining, analyzing and interpreting the data, Effective participation in research orientation, Intellectual participation in propaedeutic and/or therapeutic conduct of the cases studied, Critical review of the manuscript.
Noha Adly Saleh
(iD) ORCID
0000-0002-3167-2454

Approval of the final version of the manuscript, Effective participation in research orientation, Intellectual participation in propaedeutic and/or therapeutic conduct of the cases studied, Critical review of the manuscript.

Dedee F. Murrell

(D) ORCID 0000-0003-2971-0199

Approval of the final version of the manuscript, Conception and planning of the study, Effective participation in research orientation, Critical review of the manuscript.

How to cite this article: Saleh MA, Zaraa I, Doss N, Saleh NA, Murrell DF. Assessment of the quality of life of Egyptian and Tunisian autoimmune bullous diseases' patients using an Arabic version of the autoimmune bullous disease quality of life and the treatment of autoimmune bullous disease quality of life questionnaires. An Bras Dermatol. 2019;94(4):399-404. 